\title{
Where is Fort McMurray? The CAmera as a Tool for Assembling "Community"
}

\author{
ANDRIKO LOZOWY \\ RoB SHIELDS \\ SARA Dorow
}

Abstract. In response to the global mythology spawned by visual representations of Fort McMurray, Canada, this article examines a critical, collaborative youth project that sought oblique entry points to prevailing storylines of "community" and to what it might mean to live in the shadow of one of the world's largest resource extraction complexes. Building on visual methodologies where participants are encouraged to produce representations of home and place, we explore the two-way dynamic of the camera as a catalyst for assembling a temporary research collective and, by the same token, as a tool for composing and assaying the contours of "community." The project under consideration encouraged participants to learn skills of photography and to dynamically engage with other participants, researchers, and the place(s) of Fort McMurray around the creation and public display of images in both on-line and off-line spaces. Where possibilities of "community" are polarized, occluded, and/or overdetermined by the visual narratives of rapid resource development, collaboration around the camera helps to discern and speak back to the fault lines of community - including as they play out in the everyday lives of youth. Specific photos and the narratives around them are used to illustrate how the camera created and revealed iterations and relations of community across multiple scales, from the microcosm of the photography research group to the regional infrastructure of oil sands production. Keywords: community, collaboration, camera, visualicity, Fort McMurray

Résumé. En réponse à la mythologie mondiale engendrée par des représentations visuelles de Fort McMurray, en Alberta, au Canada, cet article examine une collaboration avec des jeunes qui cherchait des points d'entrée critiques et obliques

1. Acknowledgements: Peter Fortna, Sara House, Sara Loutitt, Eva Aquino, Rita Dizak, Goze Dogu, Jill Martin, Maher Ahmed, Norma Shaw, Dawn Gerriets, Garry Berteig, Sean McLenan, Ken, June, Jett, and Jada. Funding Acknowledgements: SSHRC Standard Research Grant, Killam Cornerstone Grant, University of Alberta Sociology, Henry Marshall Tory Chair Fund. 
aux narratives dominantes de «communauté» et de ce que celles-ci pourrait nous dire de vivre dans l'ombre d'une des plus grands complexes d'extraction des ressources. En s'appuyant sur des méthodes visuelles où les participants sont encouragés à produire des représentations de domicile et le lieu, nous explorons les deux sens dynamique de la caméra comme un catalyseur pour l'assemblage d'une collective temporaire, et par le fait même, comme un outil pour la composition et l'analyse de l'contours de «communauté». Le projet a encouragé les participants à acquérir des compétences de la photographie et de s'engager de façon dynamique avec les autres participants, les chercheurs, et des places à Fort McMurray autour de la création et l'affichage public des images dans des endroit à la fois en ligne et off-line. Où les possibilités de «communauté» sont polarisées, occlus, ou surdéterminé par la narration visuelle d'un développement rapide, la collaboration autour de la caméra permet de discerner et de parler de communauté - y compris le rôle ils jouent dans la vie quotidienne des jeunes. Des photos spécifiques et les récits qui les entourent sont utilisés pour illustrer la façon dont la caméra a créé et a révélé des itérations et des relations de la communauté à travers de multiples échelles, du microcosme du groupe de recherche photographique au niveau de l'infrastructure régionale de production des sables bitumineux.

Mots-clés: communauté, collaboration, caméra, visualicité, Fort McMurray

\section{INTRODUCTION}

ommunity is a common reference in political and media discourses and a rallying point for responses to local issues. However, what "community" refers to, and what is at stake, is an open question. In the case of Fort McMurray, the reference is as much to collective affect (Davidson et al. 2011) as to an aspiration — a struggle to both build and imagine a community in what has been called the Canadian "resource hinterland" of boom and bust resource developments (White 1979; Hechter 1975). Of course, we assume that ideas of community are multiple and emergent; community appears through practices that establish insider status (Elias and Scotson 1994), performances of belonging (Cohen 1982), and experiences of communitas, the affect of togetherness (Turner 1974). If "community" is a thing, it is virtual in the sense of an intangible good known through its effects (Shields 2006). Our aim is to explore the unintended and diverse consequences of its invocation and the different regimes of practice and knowledge that constitute it (Creed 2006). More specifically, we consider the consequences and knowledges of community made possible when a camera is used - and when photography is made the central apparatus of research - by drawing on a project that invited youth to be collaborators and co-investigators in the search to "find" Fort McMurray as place, community, and conjuncture. 
Previous work on image-based research, including photovoice and photonovellas (Wang 1999, 2001; Wang and Burris 1994), communitybased participatory research (Lopez, Robinson, and Wang 2005), and reflective and interpretive collaborative participant-based projects (Berger 1982; Pink 2001; Rose 2001; Sontag 1977), helped us find our way to the question of community via the practice of photography and the "camera as tool." However, this is not, as in the tradition of photovoice, a matter of the camera as a device for empowering the lived authenticity of community voices (Wang et al. 2000:81-89); when deployed with youth, many such projects have explicit pedagogical goals such as activating citizenship or promoting safety, and/or they set out to document a specific process. Nor is it, as in some branches of visual sociology, a concern with the camera as a methodological tool for representing or capturing community life. Rather, our project came to be about the camera as an apparatus of community - itself a kind of organizing principle, a catalyst of people-place-research relations, and thus an aid in sensing some of the extant and possible meanings of community. Szeman and Whiteman (2012:48), in a photographic essay on Fort McMurray, draw on the work of Allan Sekula to explore "the possibilities of the photographic image - its almost unprecedented capacity to provoke conceptual, theoretical and political openings as a result of its relation to the real"; we step back to ask about the rich methodological possibilities for pursuing the idea and practice of community when the camera and the photograph are used to provoke such openings.

The ironic but provocative sociological insight is that any camera as a photograph-making technology assembles subjects, photographers, and viewers around it as social groups. Thus, the camera could serve as an "inward looking" organizing principle for our collaboration as well as an "outward looking" research medium asking after emplaced community. It was an active agent of creating, refracting, and reimagining "community" as it applied, in one and the same moment, to our research collaboration - which we take to include us and the youth - and to Fort McMurray (cf. Pink 2011:92-101). In short, the camera articulated us to the youth, the youth to Fort McMurray, and us to Fort McMurray in particular ways. That articulation was furthered as the images created by the youth made their way into formal spaces such as the public displays and Flickr.com site directly facilitated by the project, as well as informal, unanticipated spaces such as personal web sites and internet postcards. As an intervention on visual sociology's usual approaches to the camera — as aid to representation of and/or for community - our paper argues for the camera and the photographic relations of practice around it as a methodology for sensing the particular configurations of people, place, 
and feeling that constitute the idea and problem of "community" (Creed 2006). In this specific context, the camera helps to sense how these configurations are virtually shaped with and against Fort McMurray as resource town and as metonym for the now visually iconic oil sands.

Participants were recruited with the question and the promise of working/learning how to operate the latest single lens digital cameras, and a medium format film camera (a Mamiya 645). Participating youth borrowed cameras for periods of a day to about a week between meeting up to take photos or discuss the images that had, and had not, been taken. These participants were, like many contemporary youth, familiar with photography as an everyday aspect of smartphones and social networking sites. We organized the project in part via a Facebook page, arranged rendezvous by text message (SMS), and publicly archived the images on Flickr. It became important to the project that participants had the opportunity to move from low-resolution, small screen mobile phone "pics" to art photography, with a promise of access to "serious" albeit not commercial photographic technology, an introduction to film processing and digital image editing, and large-format digital fine art printing. We also had some local technical assistance from interested personnel in the digital media and photography program at Keyano College in Fort McMurray.

The photo project was part of a larger study of social life in Fort McMurray, an urban centre in northern Alberta with a population between 70,000 and 100,000, depending on boom-bust cycles and varying by census source. The city has grown at the centre of the Athabasca oil sands formation, a vast deposit of bitumen underneath the boreal forests of northern Alberta that is extracted through open strip mines and steam injection (Government of Alberta 2012; VBS.TV 2008; Dyer et al. 2008). With that growth has come high mobility and high infrastructure stress. The airport and outlying airstrips support the movements of workers for the oil industry who travel from distant homes to Fort McMurray or to huge work camps at outlying mining and processing sites. Fort McMurray shares with other resource economies a clash of local culture and place with global capitalism (see, for example, Kashi and Watts 2010; Cheshire 2009). As an oil "boomtown" it illustrates the power of economics to assemble a cosmopolitan group from all over the world around an industrial task. It produces a settlement, but one where social reproduction is dependent on shift work, variations in the fortunes of oil prices, and globalized investment decisions. These realities compound the market on one hand and the face-to-face interests and projects of neighbours on the other, adding to the tenuousness of community and democracy as social realities. Fort McMurray was disincorporated as a 
town in 1995 and designated an "urban service area" within the much larger Regional Municipality of Wood Buffalo (at some 70,000 square kilometers, the RMWB covers most of the northeast corner of Alberta). The formation of this new entity ensured that the formal system of tax extraction would more fully encompass the reach of bitumen extraction, further imbricating the social relations of place with the oil resource economy.

The gaze of the camera is especially salient to the production of community in Fort McMurray, whose global notoriety has been accomplished in part through aerial visual depictions of giant tailings ponds and vast mining operations (cf. Szeman and Whiteman 2012), alongside more intimate depictions of bar scenes, bumper-to-bumper pick-up trucks, and weary coverall-clad workers. These have appeared in a special issue of National Geographic (March 2009), the widely exhibited photographs of Edward Burtynsky (2001, 2004, 2007), countless media specials such as The Globe and Mail's "Shifting Sands," and films such as H2Oil and Petropolis. Just as the very name "Fort McMurray" has become to some degree synonymous with the oil/tar sands in popular national and global imaginaries, so have these images blurred the boundaries of the oil/tar sands and the lived communities of people around them, confounding and multiplying notions of community. In the years in which our research project unfolded (2008-2010), official and unofficial community narratives - of family-friendly activities and growing recreational and charitable opportunities - were marshaled to counteract these "big lens" images of a scarred physical and social environment (Dorow and Dogu 2011). These particularly fraught politics of the visual in Fort McMurray make suspect those who arrive from elsewhere with cameras.

It was in this context that youth were invited to create their own images, to locate "their Fort McMurray." It was also in this context that what was activated by the camera in research opened us to what is at stake in the naming and disclaiming of community in Fort McMurray - including the diverse meanings and uses of the visual and its production and circulation as a media iconography. In this way our project is attentive to the multiple ways of experiencing place that might otherwise be occluded by the global hyper-visibility attendant on this singular resource economy. Much as we might not have intended it, the camera highlighted the tensions and possibilities of asking about community in this particular context; and it did so precisely because it opened the mundane political tensions and possibilities of collaborations as researchers interacted with places and participants. Fort McMurray faces contemporary versions of hyper-globalism, migrant workers, social organizations desperately trying to keep up with demand, and an economy of dol- 
lars that appears disproportionately gargantuan in relation to economies that function without such close proximity to resource extraction. Fort McMurray is a place where the scale and intensity of resource extraction, accompanied by diverse sets of cosmopolitan peoples in various states of coming and going and staying, condenses our focus on community and demands that we find other ways of asking about it. The camera and collaborative research efforts around it offer an opportunity to know community differently, and to observe how they converse and conflict with this and with other dominant forms of visualicity.

Of course, while "community" itself is not visible per se, its constituent members, activities, and infrastructure are. We are, on one hand, dealing with visual culture, but on the other, we are dealing with a regime of visualicity, a conception of visual culture or the scopic that also includes the invisible, the public secret, the overlooked and the barely glimpsed as well as the visually clichéd (Shields 2004). This allows us to speak to what is missing or suppressed rather than only what visual culture studies tends to focus on, namely, the manifestly visible. The camera collects visual samples in which collective aggregates of bodies and/or objects are composed together in and as images. As aggregates, rather than monadic objects, images can capture situations and interacting elements. That is, affect appears in the spaces between entities in any image, and it is these relations captured visually that, over thousands of photographs, assay the contours of the virtual-but-real intangibles such as community, place, and identity. These intangibles are further assayed in the "social life" of the images as they traverse and even create new social spaces.

We pursued a course of research that, via recruitment in select local high school classrooms, brought together a core group of a dozen youth. Primarily comprising young women, the group represented a range of cultural backgrounds oversimplified as First Nations, Métis, Southeast Asian, Middle Eastern, Québécois, Ontarian, Albertan. Like the adult population of Fort McMurray, these youth brought with them the multiple and shifting perspectives of community and place that come with living in a place of intense development and observing the inward and outward flow of people. Depending on where "home" was, participants variously related to Fort McMurray as a place they had lived all their lives, as a place to make money and leave, and/or as a place where one did not initially feel at home but where one eventually might. Initially conceived as a contained six-month project, the research collaboration evolved over the course of two and a half years and continues to have an on-line and public presence, with participants occupying various roles as subjects, participants, collaborators, researchers, and advocates. Multi- 
level collaboration meant an ebb and flow with one another and with variously connected individuals and groups, from the high school teachers who encouraged students to participate and the Keyano College personnel who lent the use of the photo lab, to the personal and public sites where the images were displayed.

Guided by an overarching concern with the elusive concept of community, we settled on asking participants (and also naming the project) the just-abstract-enough question, "Where is Fort McMurray?" Taken colloquially, the question asks with a deceptively broad stroke; taken literally, the questions seems to ask at geography; and taken metaphorically, we found that responses developed as introspective reflections on what it means to be in relation to a place. Depending on respondents' maturity, social location, and cultural background, "Where is Fort McMurray?" offered us a starting point to any conversation, ensuring that we would not be getting a singular response. We discuss below how our project arrived and took off from this question, and then use two particular images produced during the project to exemplify the camera as a tool for asking after community as a verb as well as a noun. As suggested above, we are interested in how the people-place-feeling relations created in the process of making images, i.e., assembled around the camera, open up the possibility of asking about the limits and possibilities of community assembled by the images themselves.

\section{Where is Fort McMurray? The Question, the Walkabouts, the IMAGES}

When we held exploratory meetings about the project with a small group of Fort McMurray teachers and school officials in early 2009, the question "Where is Fort McMurray?" seemed to resonate with them as an open, acceptable, and inviting way to shape and launch the project with youth. Given local concerns about overdetermined ideas about the place (as, for example, a wild frontier boomtown), "where" seemed to work better than "what." Would the camera lens find multiple and diverse Fort McMurrays? Would a younger, generational image of the interactions that constitute community life be exposed? Would this lie in different places/spaces and thus cut through (or at least bypass) the polarization of insider/outsider? How would it negotiate Fort McMurray's conflation with, or subsumption to, oil?

Youth were then invited into a working collaboration by way of provocation. We began by presenting to high school classrooms of both wide-eyed and shut-eyed students the dominant and alienating media 
images of the "tar sands" that appear when one uses Google images to search out Fort McMurray. Aerial views of the town site seemed to register as minor curiosities to the students as they tried to quickly determine their relative location on such images. As we scrolled by the next images of the oil sands and sites of bitumen extraction, the energy in the room changed and some of the students began to say things like, "That's where my dad works," or, "That's not Fort McMurray, that's not where we live." We would make our response by asking, "Isn't it interesting to note that via a Google search, Fort McMurray very quickly becomes geographically abstracted and shifts north and south and east and west, in every direction other than the town?" We asked the students if they thought it was curious that Fort McMurray is represented by images of places like open pit mines and upgrading facilities. The students responded with puzzled looks on their faces. So we changed tactics and brought their attention to the numerous digital cameras that we had brought along. Cameras were passed around the room so that students could get their hands on the apparatus. The students held the glass/magnesium and plastic to their faces and peered through the small focusing viewfinder. Looking through a single lens reflex camera rather than simply looking at a back-lit illuminated screen was for most of these students a novel experience. As the cameras made their way down the rows, some snapped the shutter in quick attempts to picture their fellow students. There was an excitement growing about the possibility of learning skills associated with digital and film photography. Aperture, shutter speed, film speed, ISO. With aerial shots of the oil sands, the boreal forest, city hall, and downtown still scrolling on the screen, the cameras changed hands, and we returned anew to the central question Where is Fort McMurray?: Where is it really, to you? Where do you go? What is your sense of this place? What would you want to share about it?

Some students said they liked it here, some said they hated it, some said they were just here for the money, some said their families moved out here in order to be gainfully employed. Time wound down and cameras made it back to the front of the room. Interested in attracting participants, we asked our final questions: Who wants to learn photography? Who wants to work individually and in groups to create some images of this place? Who wants to show their work at the end of the project in a public display? Who has an idea for an image? Hands went up like a shot. "I want to take a picture of Highway 63 - because it is so important to the whole town. When the road closes down, the whole town shuts down and we all have to wait." Another replied, "I want to get up to a high place, I want to go up to Gregoire [a suburban neighborhood] and picture the town as it sits amidst the forest and the rivers, because 
it really is quite beautiful here." Another replied, "It's so dusty here, I want to picture the dust, but I'm not sure how yet." In this context, image-making is not neutral; even without probing their digital technologies more deeply, images and cameras were articulated with media discourses and a broader, Big Lens visual culture.

In numerous rounds of classroom visits students within the school system of Fort McMurray were presented with an idea, a potential project - the choice to take part was up to them. The project may have seemed curious, strange, exciting, frightening, odd; but when asked, the dozen or so students who eventually made up the group (from all three public high schools, each with its own reputation and range of students) said that they came because they wanted to learn photography. They wanted to learn the skills associated with a camera that offered a level of complexity beyond what their small point-and-shoot and phone cameras could offer. In most cases the reasons and motivations for joining in the project about Fort McMurray was not evidenced as directly social. Rather, students gathered around the idea of photography. The way into the place was to create a group; the way into asking about Fort McMurray as a place and community was through photography and the weekly cycle of meeting up in small groups, looking for shots, and loaning and retrieving cameras; and the way into the pulse of youth in Fort McMurray was for a small self-selected sample to build a temporary, although not ephemeral, community of interest around the camera. The suggestion here is that cameras constitute a catalyst for all manner of generative, imaginative, and active spatial manifestations that create moments, and time-spaces that produce ordered differences (Shields 2006) through everyday activities and rituals that generate representations.

As the weeks went by we would meet up with various combinations of youth - sometimes even just one or two - at their school or the library or another agreed-upon location, depending on the day of the week. What this meant was that the researchers teaching about cameras (usually Lozowy) could have long conversations with participants that always began with the question "Where is Fort McMurray?" as a beginning framing question, followed by a few instructions on the basic functions of the camera - and then, we could pause and listen. When youth posed technical questions such as about depth of field, the transfer of knowledge was palpable, reinforced by the opportunity to practice and master in the moment.

During these walking sessions the students would suggest that they wanted to go photograph a certain place, a building, or a particular quality. When we moved in these geographically fluid ways we were participants in communitas as well as in a hunt that was motivated by students' 
own interests in picturing through the camera lens. At review sessions all of the images would get loaded onto the computer and viewed using a data projector. We could sit together as a group as different individual photographers took turns screening their own photos (we do not discuss in this context either film printing technique or digital printing and the algorithmic role of what could be called a "visual software coding culture" in predetermining the available effects on screen and paper). This gave the photographers an opportunity to self-gauge how quickly or slowly the images should be moving, as well as full control of stopping and speaking to any of their own images. In these moments the participants would have a chance to engage in conversation with one another.

It was here that potential lay for battles over presumed, pictured, and idealized notions of community to take place. Throughout the process the participants became researchers, learning from one another, agreeing, disagreeing, and making insightful comments and rebuttals within a group of similarly aged peers (Lozowy 2013). At the same time, the group included a handful of students from each of the three high schools, and thus, most students had never met each other. Much of the time discussions were quite diplomatic. Diplomacy seemed to veil the uncertainty of critically engaging with "community" amid its polarized camps of outsider and insider, hyper-visible critique and reactive defense.

\section{Two Images: “Community" in Fort McMurray}

While the images under discussion varied greatly, a few of them stood out, becoming touchstones for participants, including us, because of their frank representation of stigmatized activities. In one case, a group of three friends who spent most of their time photographing each other captured some images of the three of them as they shared a hookah. When this particular image flashed on the screen the three of them shrugged in anxious anticipation of what we might say. Instead of presuming any judgment, we opened up the conversation by simply inviting them to tell about the image. A couple of the students spoke a narrative of their own experience of self and place: "If you don't drink and do drugs in Fort McMurray then you are nobody."

This is one of the more poignant statements made about identity and place that we heard while working with the photographer participants, precisely because it makes intimate and perhaps even mundane what is otherwise a key site of anxiety about community — drugs and alcohol use - by expressing it as an admixture of status-recognition and of a kind of belonging that arises from performances of particular practices 
and shared activities. The image in question shows one of the participants exhaling with her eyes squinted. She sits in the foreground, on the floor, with her back against a bed. The day-lit but dim surroundings of the bedroom are mundane but telling. They include a bag of snacks on the bed, a poster on the wall, towels stuffed at the base of the door behind her, the tall hookah in her hand. A companion's red-sleeved arm in a front corner balances the orange of a bag of chips. The even depth of field keeps everything relatively visible and in focus so we have few clues about the priority of relations between the central figure and the interior - there is no dramatic lighting or use of a flash. The aesthetics argue against this being staged; the composition with the "accidental" arm adds to the snapshot realism. The young woman is relaxed but her eyes squint, concentrating on inhaling. Is it tobacco? Is it drugs? This is a photo that starts debates. (It also started debates within our research team. The photo is not included here due to the exigencies of research ethics, even as its exclusion raises another set of ethical questions.)

In this case, this particular group of participants has shared, in response to the question "Where is Fort McMurray?" a vital and embedded glimpse into meaning and identity politics in Fort McMurray. These youth have pictured place, have sought after community. But in so doing, they have negotiated a double imaging of community: from the inside, one of sharing a secret activity in an intimate everyday space of friendship, and from the outside, one of Fort McMurray as a temporary encampment rather than sustained community, a site where drugs-andmoney symbolize the hollowing out of social cohesion, the social excesses of resource extraction. This latter imaging of community casts these youth as abject, "at-risk" (Shields and Sharkey 2008) and in need of rescue from the very moment of communitas, of familiarity and engagement with place and with others in that place, that is being depicted. Yet here, rescue is recast as an empowering tool, as in, rescued from boredom and thrust into a world of active engagement. In other words, rather than remain as victim of prevailing aerial and resource narrative, the youth participants worked to identify their own spacings.

As unearthed in our broader research project, anxieties about Fort McMurray's youth centred around a social profusion of money and drugs that, in turn, represented the double-edged sword of economic opportunity. The cameras, their images, illuminate social fault lines around the idea of "community" which, by dint of collaboration, implicates researchers in those fault lines. These include a hypersensitivity to attacks on community from the outside - from formal and social media depictions of it as a frontier town, as no place to raise a family - or even to debates on community within Fort McMurray. These sensitivities and 
sociopolitical cleavages marked in discourse and images such as the hookah photo revealed a protocol of social science research ethics woefully unprepared for the complexities of community both encountered and produced "in the field" (see Candea 2007; Coleman and Collins 2006). In our case, the field was "found" through the question "Where is Fort McMurray?" It is local within the boundaries of the urban agglomeration, regional in that it references the Athabasca Tar Sands area, and global in the form of media critiques cited above (see Fraser 2007).

The photograph with the hookah did not go away; rather, it became one of the images that the students decided they wanted to include in a first, private showing. The participants responsible for the image made their own decision and justified why they wanted to show it - for them this image represented the social world that they inhabit, enact, and live through. It lived next to pictures of other social worlds - swing sets, the busy highway, backwoods trails, downtown intersections, workers waiting for the bus. This mini exhibition was the first big milestone of the project. "Where is Fort McMurray?" was first on display at Keyano College in Fort McMurray, and held in the very room that we had used to meet, share images, learn photo editing on the iMacs with Photoshop, print the images (thanks to the College's large format printer), and finally show them off. Later these images were put on prominent display on the walls of the brand new public library (attached to the much-celebrated Suncor Community Leisure Centre). Whereas youth participants were unsure initially about having their work exhibited to the public, a year and half after the photography project they had enough enduring sense of themselves as a group and the experience as a project that they had precisely this interest. The images on display continue to act as provocations in their own right. By this we mean that when locals, or folks who are new to Fort McMurray come in and have a look, these images may provoke a series of questions: Where did these images come from? What about the images that didn't make it up here? What else, or what's missing? And with luck, someone will come by and say, I can do better, I can respond.

Photographs and, during the project, the camera, became the social meeting point. In other words, the camera as an apparatus (Flusser 2000) became the black box with which we could follow through with a certain kind of technicality and glean some information about the process and the product. Simply put, cameras gave students/youth in Fort McMurray the opportunity to hold, think, look, observe, photograph, picture, imagine, discuss, lead, follow, explore, and begin to express their own individual and oftentimes critical perspective of what, where, when, why, who, and how Fort McMurray is represented and lived. We discovered 
that the camera was the provocation, a catalytic agent providing an occasion for assembling community: the collective learning and walking, the sharing of images in public exhibits and personal websites and informal workshops, the composing and configuring of relations of people-placefeeling in the images themselves. The takeaway here is that participants had the opportunity to etch their own representations of Fort McMurray onto place, and thus resignify that which may have previously been predetermined and out of reach. The camera became a tool for engagement - mastery, even.

For Flusser, an image is based on the chance situation of the snapshot but is then created and distributed mechanically by programmed apparatuses. The photo is an image of a frozen, magical glance at a state of things that would otherwise be unremarked upon, slipping past the gaze (Flusser 2000:76; Shields 2004). This is because photography is understood to construct the momentary situation of matter and movement as the visualization of an event. It is able to perform this translation because Flusser's "apparatus" is an institution, an interdependent set of interactions which produces its own mode of knowledge and its own truth-effects through what is revealed rather than via reference to a preexisting set of moral judgments such as those on community. By implication, it intervenes against existing dispositions of power-knowledge by allowing the youth to deploy the camera's own regime of power. With almost all of the youths' images one witnesses a struggle that goes beyond the register of representation to the real - both material and virtual - as what is truly at stake. It is a way of sensing (Shields and Lozowy forthcoming).

The relationship of inside and outside is germane: the hookah photo is just a kid in a bedroom, but that it is a bedroom in Fort McMurray is what matters because this is the image that is to be suppressed, hidden, given that it represents a minor, identifiable participant in the project, and suggests a social excess that can't be contained. This image documents and locates it, speaking back to that anxiety. The image echoes the "opportunity and growth" theme of some of the media images, but again in a kind of mundane, intimate, unsensationalized way. The image with the hookah affectively pulled researchers and participants alike into the intimate anxieties of community in Fort McMurray, and then cut right through them with its mundane documentation.

A second image almost moved in the other direction, from a seemingly mundane documentation of "growth" toward a set of troubling questions about its implications for community. An image of a large dump truck or heavy hauler being used in the construction of new suburban infrastructure (Figure 1, see Shields 2012) was created by a mem- 


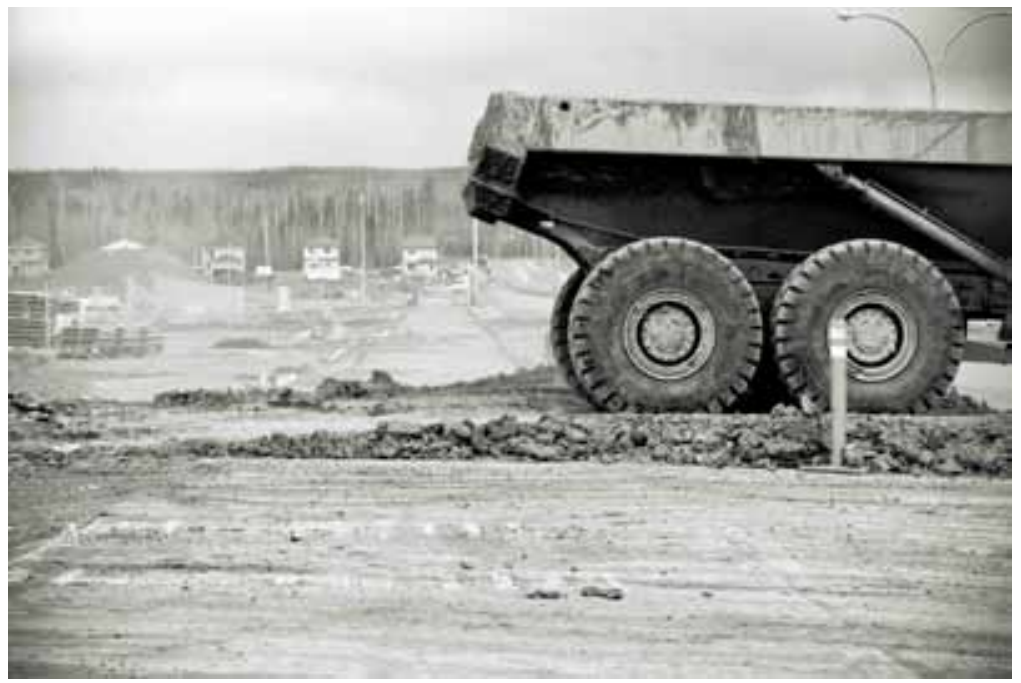

\section{Figure 1. by Milauni Desai}

ber of the group who demonstrated a keen willingness to be a part of the project from the beginning. Even on one occasion when no other students showed up, Milauni was happy to learn what she could and to walk me (Lozowy) around nearly the entirety of Fort McMurray. As we walked, and rode the bus, and even made a stop at the mall so she could pick something up, she asked questions about how to do particular things with the camera. As I helped her to practice and refine techniques, she spoke to me in a very open and candid way about this place that she now calls home; at the time, she had been in Fort McMurray for maybe two years. When we first met in 2009, Milauni was motivated to photograph the dirt and dustiness of Fort McMurray. She lived in a newly built suburban home in Eagle Ridge, touted as the city's first fully "planned community," where the latest mixed housing developments were being carved out of the boreal forest in an attempt to keep up with the impossible growth in demand for housing. She would tell me about the fact that, even with the windows and doors of the house closed, there would soon appear a fine layer of silty dust on virtually every surface. And so, she said, she had wanted a way to represent two prevailing and pervasive themes: a) the silty dust that manages to get into one's house even when the windows are closed, and b) the observatory reflection, based on the position of her bedroom window, with a view to the development and construction of Eagle Ridge, that "it's happening too fast." She wanted to represent the place, the community, her perspective of place, as one that is perpetually dusty, perpetually under construction. 
The "suburban heavy hauler" image emerged out of a series of images that Milauni created one day while she noticed a particular amount of movement going on with the trucks and construction vehicles that could be seen out her back window. The series of images sees her moving away from her house on foot, until she reaches a particular angle, the place wherein everything lines up. All manner of juxtaposition reaches its fever pitch. There is a solidity and a clarity in the image that insists on a pause from the onlooker. In Figure 1, there is a sense that this series captures a very temporary moment: the truck is in motion, the moment is destined to repeat, the machine does the job it was designed to do. We are at the site and event of the production of the suburb as "second nature" where even the topsoil will be artificial. The machine crosses a foreground scarred and scraped of its natural surface, caught just exiting the photo as a dark mass of angular metal and tires. Hazy through the trailing dust one sees a field of new streets, sidewalks, and lamp posts, and in the distance the type of row of two-storey houses this site will become. Almost a blur, still further in the background behind the houses is a dark band - the raw edge of the aspen and spruce forest in which (locals know) lie the tar sands sites only some $10 \mathrm{~km}$ distant. Printed in black and white, no colours enliven the horizontality of this composition. It effectively positions the viewer in the dangerous proximity of the heavy hauler with the domestic infrastructure of human community on the far side of industrial construction activity.

There is something curious happening here as well, there is a heaviness, perhaps that of the house-sized machine that outweighs the residential neighborhood. In this moment one can recognize that this is indeed Fort McMurray, because this machine is the surplus form - a social simulacrum of an extractive process that takes place in an ongoing way just to the north. This machine was built to carry an enormous burden of the weight of earth uncovered to reveal bitumen. It is a stark contrast with the lightweight construction of wood-frame suburban houses. However, as the scale of the machines that are now used in oil sands mining have grown to gargantuan proportions, these smaller but nonetheless disproportionately large heavy haulers (Lozowy 2012) have "escaped" and found their way into the town via surplus equipment auctions. Youth in Fort McMurray have little contact with the realities of either open pit mines or the drilling and maintenance of steam injection wells that, from the air, can be seen to grid the forests. As a result, surplus haulers blend with any other yellow-painted construction equipment, but by their size they add an eerie, unheimlich quality of out-of-placeness into the construction zones of suburbia. It is this contrast we see in the photo. It is this contrast, this tension, that belies a direct translation from the pace 
and growth and wealth of oil production into the sheltered "good life" of suburban community.

\section{Assembling Community: The Camera as Catalyst}

"Photographs cannot be studied in isolated form, but rather must be linked in multiple and complex ways to other forms of material evidence" (Schwartz and Ryan 2003:7). The multiple and complex material evidence is in the series of steps along the way, without which the images might emerge as fetishized objects that, in turn, fetishize the place — an eventuality made all the more inviting by Fort McMurray's already overdetermined global notoriety. The images that emerge from the series and the question "Where is Fort McMurray?" work as a set of processional results against fetishization and instead, the intent here is to provide a grounded and detailed account of what it means to activate the question as an exploration of community.

Over the course of the two years of active project time we discovered that the camera was a tool for apprehending the people-place-feeling of "community" precisely because it was the catalyst for communitas. This dual action is a manifestation of Flusser's idea of the camera as an apparatus that makes events out of the flow of everyday life and community, through the people, questions, places, and practices that it assembles. As researchers we started on the outside, from our university base in Edmonton, with a few questions about how "community" is conjured, captured, and/or denied by people living in this place called Fort McMurray. As we moved inwards, we employed some techniques of visual methods and active forms of social engagement to cultivate an active response with an "inner circle" of youth. Both amongst participants and as images on public display, the photographs provoked and continue to provoke comment through their content, through their presence in informal online spaces and in the "serious" local institution of the public library, and through their juxtapositions (in the library, for example, a section label for shelves of "Young Adult Fiction" is ironically close to the framed pictures). In other words, we have worked together in communitas with young people, in a community that is of interest, to learn about the various faultlines and storylines of that community, to learn about these through the flows and patterns of young people, to emerge with a story of process and engagement, and finally to offer photographs as a "conversation with other than words."

Of course, this was a community of interest to us because of what Fort McMurray is and is imagined to be: boomtown, economic engine, 
oil capital, cosmopolitan backwater, work destination. In that vein, we have attempted to illustrate the connections between a place of global hyper-visibility, methods of inquiry at the level of visual analysis, and the co-production of visual artefacts as emergent and temporary constructions, sites, and representations of community. Our objective has been a constant practice of tuning in to numerous perspectives. In this way we have taken our cue from practices of photography that suggest a multilevel look at a given subject. From our starting point at the university in Edmonton, we could only take in visual and oral representations of place that flow along the corridors and pathways of media representations, corporate representations, and occasional activist images aimed at offering counter perspectives to the former two streams. Images such as those in Burtynsky's "Oil Sands" series and National Geographic's March 2009 exposé on Fort McMurray contribute to a kind of externalized public knowledge. This public, or common, knowledge is precisely what we as researchers hoped to explore and challenge, to hold up to the youth as an object of interest and interlocution. The danger with floating, external, and public knowledge is perhaps that this is where narratives of power and place become strong, and often polarized.

Hyperbolic and polarizing images are part of the social fact of the oil sands, the effects of which are real in how they inform the way "community" can be imagined or emplaced in Fort McMurray. The stories of the two images told herein provide different and partial ways in to assaying those effects. The first assembles a relation of people-place-feeling around that which is supposed to represent the potential hollowing out of community wrought by rapid resource development. It tells an intimate, mundane, inside story that both reveals and flies in the face of anxiety over youth drug culture. The second takes something as seemingly commonplace as building a suburban housing community and makes it into not a haven from, but a corollary to, and almost a metaphor for, oil development: through dust, through pace, through size.

Cameras creating community refers to the multiple and fluid ways in which visualicity, the seen and the unseen, colludes with stratified, leaky, affective patterns of thought, speech, action, memory, and storytelling - as the basis for phenomenological expressions. Simply put, the youth participants cannot help but feel the effects, the leitmotifs, of cultural tropes dominated by oil, money, and growth. The youth participants worked with cameras through visual means to actively represent individual experiences rendered as images. A conversation with otherthan-words here refers to the fact that word-based conversations follow, as a second order, a more highly contested and perhaps petty forum for transmitting truth claims about being in the world. Making photographs 
and the resulting images require us to work up anew our personal formulations and enunciations of what is seen to be taking place in what amounts to a moment of second thought or a new encounter with the place in both its material and virtual aspects (such as community).

As we struggle to articulate affect, the two images in this paper offer a glimpse in both mundane and banal ways into a project that both flourished and found difficulty — the difficulty of studying social process. It seemed in this case to boil down to the simple act of inviting youth to produce images in a subdominant space and to a practice that made possible a) another kind of community and b) sideways discernment of that which binds and fixes community, especially one fixed by dominant images. Communitas-by-camera reveals the processes of constituting community while it makes the artifice involved in representation clear to participants. It also shows how community is articulated not only to shared social process (taking pictures) but also to place and to temporalspatial routines that become the subject of the photos. Cameras as an apparatus of community thus take us to the frontiers of the sociological questions that can be asked and that are amenable to research.

\section{REFERENCES}

Berger, J. 1982. Ways of Seeing. London: BBC, Penguin Books.

Burtynsky, E. 2001, 2004, 2007. Alberta Oil Sands (Series). www.edwardburtynsky.com

Butala, S. 2005. Saskatchewan: Uncommon Views. John Conway (photographs). Edmonton, AB: University of Alberta Press.

Candea, M. 2007. Arbitrary locations: In defence of the bounded field-site. Journal of the Royal Anthropological Institute 13(1):167-184.

Cheshire, Lynda. 2010. A corporate responsibility? The constitution of fly-in, flyout mining companies as governance partners in remote, mine-affected localities. Journal of Rural Studies 26:12-20.

Cohen, Anthony Paul. 1982. Belonging: Identity and Social Organization in British Rural Cultures. Manchester: University Press.

Coleman, S. and P. Collins. 2006. Locating the Field: Space, Place and Context in Anthropology. Oxford and New York: Berg.

Creed, Gerald 2006. Reconsidering Community. The Seductions of Community: Emancipations, Oppressions, Quandaries. Santa Fe, NM: School of American Research Press.

Davidson, T., O. Park, and R. Shields, eds. 2011. Ecologies of Affect. Waterloo ON: Wilfred Laurier University Press. 
Dorow, Sara and Goze Dogu. 2011. The spatial distribution of hope in and beyond Fort McMurray. In T. Davidson, O. Park, and R. Shields, eds., Ecologies of Affect. Waterloo, ON: Wilfred Laurier University Press.

Dyer, S., J. Moorhouse, K. Laufenberg, and R. Powell. 2008. Under-Mining the Environment: The Oil Sands Report Card. The Pembina Institute. pubs. pembina.org/reports/OS-Undermining-Final.pdf.

Elias, N. and John Scotson. 1994. The Established Outsiders. London: Sage.

Essick, P. 2009. Scraping the bottom: The Canadian oil boom. National Geographic Magazine.

Flusser, V. 2000. Towards a Philosophy of Photography. London: Reaktion Books.

Fraser, A. 2007. Coded spatialities of fieldwork. Area 39(2):242-245.

Government of Alberta. 2012. Alberta's Oil Sands. www.oilsands.alberta.ca.

Hechter, M. 1975. Internal Colonialism. London: Routledge Kegan Paul.

Kashi, E. 2010. Curse of the Black Gold: 50 Years of Oil in The Niger Delta. Michael Watts (ed). Powerhouse Books: Brooklyn New York.

Lopez, e., E. Eng, N. Robinson, and C. Wang. 2005. Photovoice as a communitybased participatory research method. Pp. $326-348$ in B. Israel, E. Eng, A. Schulz, and E. Parker, eds., Methods in Community-based Participatory Research for Health. San Francisco: Jossey-Bass.

Lozowy, A. 2012a. Fort McMurray — Library Series. www.whereisfortmcmurray.com.

2012b. Mega-haulers. In C.A. Zimring, ed., The Encyclopedia of Consumption and Waste. Thousand Oaks, London, New Delhi: Sage. 2013. Icons of Oil: The Photographer Researcher and Collaborative Practice. (Thesis)

Parr, Joy. 2010. Sensing Changes: Technologies, Environments, and the Everyday, 1953-2003. Vancouver: UBC Press.

Pink, S. 2001. Doing Visual Ethnography. London: Sage.

2011. Amateur photographic practice, collective representation and the constitution of place. Visual Studies 26(2):92-101.

Rose, G. 2001. Visual Methodologies. London: Sage.

Schwartz, J. and James R. Ryan, eds. 2003. Picturing Place: Photography and the Geographical Imagination. London, New York: I.B. Taurus.

Shields, R. 2004. Visualicity. Visual Culture in Britain 5(1):23-36. 2006a. Knowing space. Theory Culture Society 23:147-149. 2006b. Virtualities. Theory Culture \& Society 23(2-3):284-286. 2012. Feral suburbs. International Journal of Cultural Studies 15(3).

Shields, R. and A. Sharkey. 2008. Abject citizenship — rethinking exclusion and inclusion: Participation, criminality and community at a small town youth centre. Childrens' Geographies 6(3):239-256. 
Shields, R. and A. Lozowy. (forthcoming). Mashups: New Representations of the City.

Sontag, S. 1977. On Photography. New York: Doubleday.

Szeman, I. and M. Whiteman. 2012. Oil image(e)inaries: Critical realism and the oil sands. Imaginations 3(2):46-67.

Turner, Victyor Witter. 1974. Dramas, Fields, and Metaphors: Symbolic Action in Human Society. Ithaca, NY: Cornell University Press.

VBS.tv. 2008. Toxic Alberta. Part 9 of 15. Retrieved 5 December 2008 from http://www.vbs.tv/video.php?id=1078605950.

Wang, C., J. Cash, and L. Powers. 2000. Who knows the streets as well as the homeless? Promoting personal and community action through photovoice. Health Promotion Practice 1(1):81-89.

Wang, C. and M.A. Burris. 1994. Empowermeant through photo novella: Portraits of participation. Health Education and Behaviur 21(2):171-186.

Wang, Caroline. 1999. Photovoice: A participatory action research strategy applied to women's health. Journal of Women's Health 8(2):185-192.

2001. Photovoice ethics: Perspectives from Flint photovoice. Health Education Behaviour 28:560-572.

White, P.M. 1979. A Heartland-Hinterland Analysis of images of the Canadian North as Frontier, Wilderness and Homeland. Thesis. Carleton University, Ottawa.

Andriko Lozowy (PhD Candidate, Sociology, University of Alberta) is photographer-researcher, interested in questions of community, spatialization, geography, collaboration and arts-based methods.

Sara Dorow (Associate Professor, Sociology, University of Alberta) teaches and conducts research in the areas of globalization and transnationalism, gender and racialization, oil and community, and qualitative methods.

Rob Shields (Henry Marshall Tory Chair and Professor, Sociology, University of Alberta) directs the City-Region Studies Centre. His research includes urban culture and the sprawl of northern settlements. 